\title{
Titania Effect on Sintering behavior of Alumina
}

\author{
Qasid Abdul Sattar Saleh*
}

\author{
Date of acceptance $15 / 4 / 2009$
}

\begin{abstract}
The sintering behavior of Alumina was investigated by adding $\mathrm{TiO}_{2}$. The addition of $\mathrm{TiO}_{2}$ lowered the sintering temperature of the Alumina compared with those of pure Alumina. The result suggests that $\mathrm{TiO}_{2}$ acts as an activator for sintering of Alumina. Water absorption, apparent porosity and density were examined for both pure and $\mathrm{TiO}_{2}$ added to Alumina samples. The variations of sintering behavior were discussed in terms of shrinkage, porosity, water absorption and density. Thermal shock resistance was also examined. In term of this work, the way of improving the thermal shock resistance in oxide- based materials by adding reactive Titania powder to the Alumina samples. The laboratory results showed an improvement in thermal shock resistance property of the products which open the horizon of development of the final products.
\end{abstract}

Key words: alumina, titania, liquid phase sintering, thermal shock resistance.

\section{Introduction}

The sintering process of ceramics without additives is extremely difficult due to the low diffusivity in the solid state which follows from the covalent nature of the bonding. To overcome these difficulties in sintering, compounds are added which create a liquid phase during densification and this process is referred to as liquid phase sintering (LPS).

During LPS, the liquids formed must wet the solid particles, and particle movement and densification occur therefore by capillary pressure[1]. Kingery proposed that densification in the presence of liquids occurs by three distinct processes. The first stage is referred to as particle rearrangement in which the liquid formed reduce interparticle friction, exert capillary pressure, and promote particle rearrangement. The liquids produced also provides a suitable medium for the second stage of densification

(sintering), which is solution and reprecipitation (solution and reprecipitation may overlap in time with the rearrangement stages). The final stage of the kingery model is pore closure.

\section{Theory}

Overall densification is the change in porosity or density from the green to the fully sintered state. The upper temperature limit of the vitrification depends upon the kind of refractory material and impurities. During the vitrification period the porosity of the mass decreases with small reduction in its external dimensions.

According to the Coble equations [2]:

$$
p_{s}=\stackrel{\rho g}{\left(1-\frac{\delta \mathrm{L}}{\mathrm{L}}\right)^{3}}
$$

where $\boldsymbol{\rho}_{\mathrm{s}}$ is the sintered sample density, $\boldsymbol{\rho}_{\mathrm{g}}$ is the green sample density, and $\frac{\delta \mathrm{L}}{\mathrm{L}}$ the linear shrinkage in length. For a

*Al-Nahrain University/College of Science / Physics department. 
cylindrical sample, there will be shrinkage along the diameter $\mathrm{D}$ and the length of sample, so the corresponding equation is as follows:

$$
\frac{\delta \mathrm{V}}{\mathrm{Vo}_{0}}=1-\left(1-\frac{\delta D}{D_{o}}\right)^{2} \quad\left(1-\frac{\delta L}{L o}\right)
$$

where $\frac{\delta D}{D e}$ the linear shrinkage in diameter and $\frac{\delta \mathrm{V}}{\mathrm{V}_{0}}$ the shrinkage in volume

As we use semi - dry pressing, we have small change in dimensions. For small changes, the extent of linear shrinkage is dependent on time to the power of $\mathbf{1 + Y}$ which is slightly greater than unity, shrinkage $(\mathbf{S})$ is given by;

$$
\frac{\delta \mathrm{L}}{\mathrm{L}}=A \mathbf{T}^{1+\mathrm{Y}}=\mathbf{S}
$$

where $\mathrm{A}$ is a constant. The time required for rearrangement is too short to verify equation (3) accurately [3].

\section{Experimental Procedure}

High purity alumina (94\%) with the composition shown in table (1) was chosen for the study. $\mathrm{TiO}_{2}$ was added as weight percentage of the alumina (2, $5,10,15$, and 20) $\%$. The green samples were prepared by the semidry pressing method using a hydraulic press and a moulding pressure of 500 $\mathrm{kg} / \mathrm{cm}^{2}$.

The samples had cylindrical shape ( $2 \mathrm{~cm}$ diameter with $2 \mathrm{~cm}$ height) for testing.

After moulding, the green bodies were burned from $1200-1500{ }^{\circ} \mathrm{C}$ at a rate of $3^{\circ} \mathrm{C} / \mathrm{min}$ and investigated for water absorption, apparent density, and apparent porosity by assuming a theoretical density for alumina of 3.97 $\mathrm{g} / \mathrm{cm}^{3}$.

Table(1):Chemical analysis of (ppm) for alumina powder used.

\begin{tabular}{|c|c|c|c|c|c|c|c|}
\hline $\begin{array}{c}\text { Impurity } \\
\mathrm{Na}_{2} \mathrm{O}\end{array}$ & $\mathrm{MgO}_{9}$ & $\mathrm{SiO}_{2}$ & $\mathrm{Fe}_{2} \mathrm{O}_{3}$ & $\mathrm{CaO}$ & $\mathrm{SO}_{3}$ & $\mathrm{CuO}$ \\
\hline $\begin{array}{c}\text { Abundance } \\
(\mathrm{ppm})\end{array}$ & 20 & 19 & 82 & 30 & - & - & 12 \\
\hline
\end{tabular}

\section{Results and Discussion}

Experimental results on sintering of the alumina products, presented in fig(1), show that sintered density increased with shrinkage and was homogeneous along both the diameter and length of the product during sintering process. Around 20\% linear shrinkage on both the diameter and length was observed for fully densified material. Alumina product was heated at different temperatures for soaking time 2 hours. The results presented were obtained by measuring the length and diameter before after sintering. For the green products, experimental shrinkage density behavior was found to be in a good agreement with the theoretical values calculated from equation(1). While the experimental results on sintering of the alumina samples which listed in table(2) indicates that weight losses by burning, and apparent density increases with increasing firing temperature.

In other side, water absorption and apparent porosity will decreases. Also fig(2) and fig(3) shows that water absorption and porosity decreases with increasing the $\mathrm{TiO}_{2}$ content respectively.

So, we discount the effects of porosity by higher addition of $\mathrm{TiO}_{2}$ to the alumina product $\left(\mathrm{TiO}_{2}\right.$ is sometimes used as a sintering aid) [4].

Table(2):Physical properties of alumin aproducts.

\begin{tabular}{|c|c|c|c|c|}
\hline Firing temp. ( $^{\circ}$ ) & 1200 & 1300 & 1400 & 1500 \\
\hline $\begin{array}{c}\text { Prorerty } \\
\text { Weight loss by } \\
\text { burning \% }\end{array}$ & 5.65 & 6.25 & 7.05 & 8.35 \\
\hline $\begin{array}{c}\text { Apparent density } \\
\left(\mathrm{g} \text { cm }^{3}\right)\end{array}$ & 2.68 & 2.86 & 3.24 & 3.84 \\
\hline Water absorption \% & 34.33 & 31.21 & 29.41 & 27.22 \\
\hline $\begin{array}{c}\text { Apparent porosity } \\
\%\end{array}$ & 42.23 & 39.86 & 34.51 & 33.32 \\
\hline
\end{tabular}

Table (2) show the weight losses by burning, water absorption, apparent density, and apparent porosity of the 
refractory products, while table (3) showed that the weight losses by burning and water absorption decreased with increasing of the amount of $\mathrm{TiO}_{2}$ added to the alumina samples, though the first one increased by increasing of firing temperature and the second will decrease. As the samples were heated at different temperatures, porosity and density decreased with increasing both of $\mathrm{TiO}_{2}$ content and firing temperature.

Table (3): weight losses by burning and water absorption at $(1200,1500)$ ${ }^{\mathbf{0}} \mathrm{C}$ firing temperatures

\begin{tabular}{|c|c|c|c|c|c|}
\hline \multicolumn{2}{|c|}{$\begin{array}{c}\text { Material wt. } \\
\%\end{array}$} & \multicolumn{2}{c|}{$\begin{array}{c}\text { Weight loss by } \\
\text { burning \% }\end{array}$} & \multicolumn{2}{c|}{$\begin{array}{c}\text { Water } \\
\text { absorption \% }\end{array}$} \\
\hline $\begin{array}{c}\mathrm{Al}_{2} \mathbf{O} \\
3\end{array}$ & $\begin{array}{c}\text { TiO } \\
2\end{array}$ & $\begin{array}{c}1200^{\circ} \\
\mathrm{C}\end{array}$ & $\begin{array}{c}1500^{\circ} \\
\mathrm{C}\end{array}$ & $\begin{array}{c}1200^{\circ} \\
\mathrm{C}\end{array}$ & $\begin{array}{c}1500^{\circ} \\
\mathrm{C}\end{array}$ \\
\hline 98 & 2 & 4.10 & 5.3 & 28.3 & 18.5 \\
\hline 95 & 5 & 2.56 & 4.7 & 27.5 & 18.8 \\
\hline 90 & 10 & 1.50 & 3.1 & 24.4 & 17.7 \\
\hline 85 & 15 & 0.50 & 2.0 & 22.8 & 16.4 \\
\hline 80 & 20 & 0.25 & 1.2 & 21.5 & 15.8 \\
\hline
\end{tabular}

Fig (2) and Fig (3) show the effect of added $\mathrm{TiO}_{2}$ on the porosity and water absorption of the refractory alumina product. Both figures showed that they were decreased with increasing $\mathrm{TiO}_{2}$ content in the product. Figure (4) show that sintered density of the refractory product increased with firing temperature, also it is increased with increasing $\mathrm{TiO}_{2}$ content fig.(5). Fig.(6)

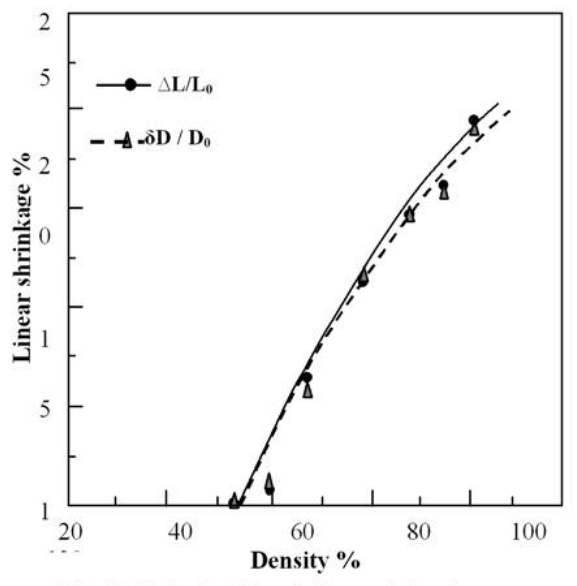

Fig.(1): Relationship of sintered density against shrinkage and diameter of show the porosity decreased with increasing $\mathrm{TiO}_{2}$ content.

\section{Thermal shock resistance}

As the resistance against temperature change is one of the most important properties for the performance of refractory product in practical applications when its exposed to rapid changes in temperatures. This temperature change contributes greatly towards loosing the product structure which causes a subsequent cracking. Thermal shock resistance was determined according to ASTM C 1259-94 [5] using cylindrical specimens.

The specimens were placed in a furnace heated at $900{ }^{\circ} \mathrm{C}$ for duration of 15 minutes. Rapid quenching was accomplished by dipping in cold water. During the test, the specimen was checked after each cycle for cracks or other visible changes in its structure. Frequently, actual failure of the specimen is reached after a large number of cooling and heating cycles only. The alumina specimens tested withstood (10) cycles without major damage. While the specimens with $\mathrm{TiO}_{2}$ content withstood (11-13) cycles without major damages because they were following the ratio of $\mathrm{TiO}_{2} /$ Alumina.

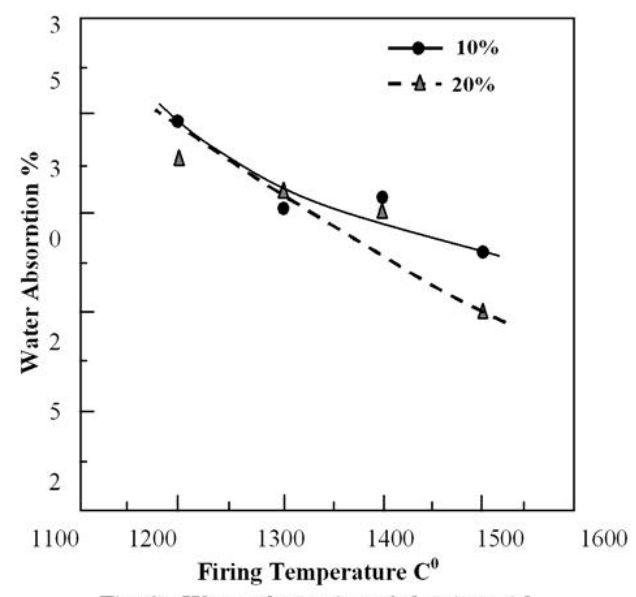

Fig.(2): Water absorption of alumina with $10 \%, 20 \% \mathrm{TiO}_{2}$ content. 


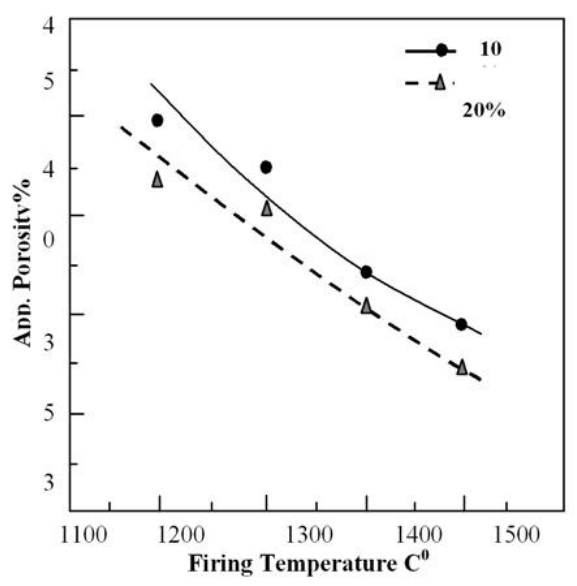

Fig. (3): Apparent porosity of alumina with $10 \%, 20 \% \mathrm{TiO}_{2}$ content.

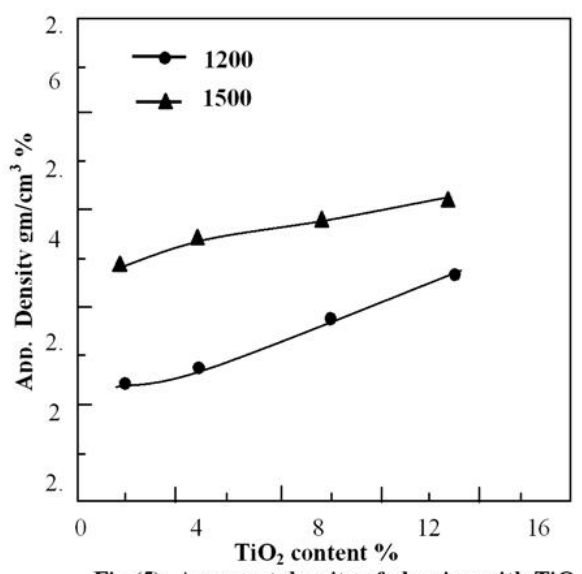

Fig.(5): Apparent density of alumina with $\mathrm{TiO}$ content for $(1200,1500)^{\circ} \mathrm{C}$ firing temperatures.

\section{Conclusions}

It has been shown that the sintering of alumina products would effected by an addition of Titania as follows:

* The higher temperatures and possibly the $\mathrm{TiO}_{2}$ addition enabled all the samples to reach near full density.

* As expected, the degree of sintering increased with increasing the firing temperatures as well as increasing

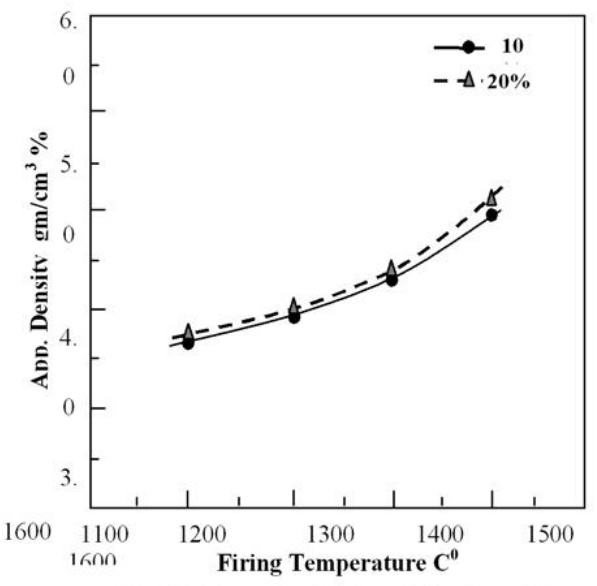

Fig.(4): Apparent density of alumina with $10 \%, 20 \% \mathrm{TiO}_{2}$ content.

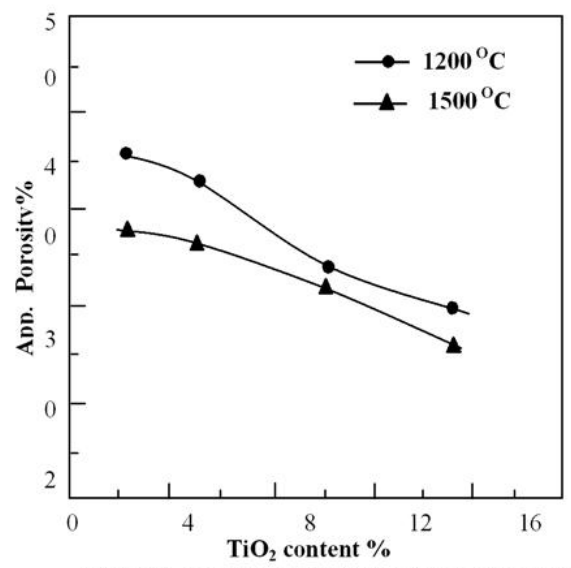

Fig.(6): Apparent porosity of alumina with $\mathrm{TiO}_{2}$ content for $(1200,1500)^{0} \mathrm{C}$ firing temperatures.

the $\mathrm{TiO}_{2}$. At low temperatures $\left(1200{ }^{\circ} \mathrm{C}-1400{ }^{0} \mathrm{C}\right)$, the products was poorly sintered which resulted in a porous product mainly aluminsilicate while at a firing temperatures up $1400{ }^{\circ} \mathrm{C}$, a liquid phase formed indicating completion of the sintering process.

This liquid phase formed a glassy phase during cooling and contained some alumina crystals[6]. 
* The effect of Titania additions at the $10 \%$ and $20 \%$ was observed to the reaction sintered of alumina samples, where firing behavior is mainly effected by minor components supplying fluxing (i.e. iron, alkaline, and alkaline- earth) oxides [7].

* We conclude that $\mathrm{TiO}_{2}$ can be used as a sintering aid for alumina and some other refrectory materials and in the same time in improving to the some of thermal properties such as thermal shock resistance of the material.

* To obtain product with better performance we need to firing temperatures further than $1600{ }^{\circ} \mathrm{C}$ to complete the glassy phase which depend on the ratio $\mathrm{TiO}_{2} /$ Alumina.

\section{References}

1. Edrees H.J. and Hendry A. 1999," Shrinkage and densification of particulate reinforced ceramic matrix composites",Br. Ceram. Trans.,98 (1):6-11.

2. Coble R. L. , 1961, "Euro ceramics: Processing of Ceramics", J.Appl. Phys., 32:793-797.

3. German, R. M., 1985, "Liquid phase sintering", plenum press, New York, pp. 246

4. Alford N. McN., Wang X., Penn S.J., Poole M., and Jones A., 2000, "Effect of ceramic binders on microwave dielectric loss of alumina", Br. Ceram. Trans., 99 (5): 212-214.

5. "Annual book of ASTM Standards", 1995, 15(2), ASTM standard C 1259- 1294, philadelfia.

6. Sebbani M. J. E., Allaire C., and Ntakaburimvo N., 2000, Influence of firing temperature on correlation between thermal shock and mechanical impact resistance of refrectory castables ", $\mathrm{Br}$. Ceram. Trans., 99 (5): 215-218.

7. Dondi M., Lglesias C., Domingues E., Guarini G., and Raimondo M.A., 2007, Applied clay. Science, 40:143-158

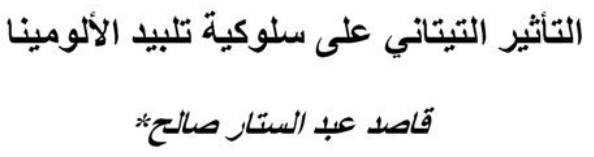

$$
\text { |قسم الفيزياء / كلية العلوم/ جامعة النهرين الجادرية، بغداد، العراق. }
$$

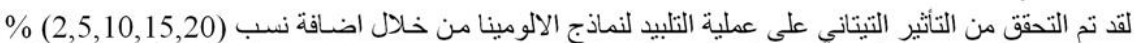

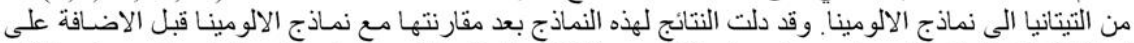

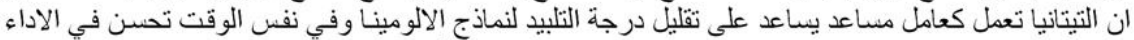

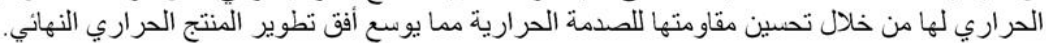

